Laboratorio de Arte, 7-1994 http://dx.doi.org/10.12795/LA.1994.i07.06

\title{
ORFEBRERÍA ITALIANA EN SEVILLA (I)
}

\author{
POR María Jesús Sanz SeRrano
}

\begin{abstract}
Se recogen y estudian un grupo de obras de orfebrería italiana que se hallan en la ciudad de Sevilla y en la provincia, entre las que destacan las piezas de la Catedral, que resultan las de mayor calidad e importancia. Aunque algunas obras habían sido ya estudiadas previamente, ahora se presentan nuevas propuestas de fechas y autorías, así como diseños previos a la realización de alguna de ellas.
\end{abstract}

One present an study of a group of italian silver pieces standing in the city of Seville, and also in its province. Among them the cathedral's colection is the main one. Nevertheless some of the pieces have been studied before, now one present new propositions of dates and authors, and so previous desings of some of them.

Las relaciones culturales y artísticas entre España e Italia constituyen un tema estudiado y debarido en abundantes publicaciones, congresos, reuniones y jomadas. No obstante restan muchas facetas, especialmente relacionadas con los contactos artísticos, por aclarar.

La relación entre ambos países es tan antigua como la misma historia de ellos, pues todos sabemos que nuestra cultura es romana en todos sus aspectos fundamentales. Nos interesan, sin embargo, períodos más cercanos a nuestros días, cuandó ambos países tenían ya una entidad distinta y afirmada, como ocurría ya en el Medievo. En esta etapa los contactos de las distintas repúblicas italianas con los reinos levaninos españoles fueron siempre continuos, pues no en vano el Mediterráneo fue la principal vía de comunicación desde la Antigüedad hasta la Edad Moderna para los países ribereños. Sin embargo, a partir del siglo XVI la influencia italiana en España va a ser definitiva en el campo de las Artes. Este flujo cultural tiene motivaciones políticas, relacionadas con conquistas de territorios y problemas dinásticos, pero indudablemente estas situaciones originaron el trasvase de hombres y de ideas de uno a otro lado del Mediterráneo, y como consecuencia un trasvase cultural.

Con respecto a los reinos y repúblicas italianas puede decirse que los que van a estar más vinculados culturalmente a España van a ser el los del norte y los del sur. Los del norte porque van a ser el escenario de las luchas entre españoles y 
franceses por el dominio de la Lombardía y el Milanesado, a lo largo de los siglos XV y XVI, y los del sur, mejor dicho, el del sur -el Reino de Nápoles-, porque estuvo vinculado a la casa de Aragón desde el siglo XIV hasta casi la época de la unidad italiana, aunque con varias interrupciones dinásticas.

En el Arte de la Platería los contactos entre España e Italia resultan bastante complejos, y si bien sabemos que Felipe II tuvo a figuras como los Leoni y Jacopo Trezzo en su Corte, no está suficientemente aclarada la influencia que ejercieron entre los orfebres españoles, salvo en el caso de Juan de Arfe, que ya tratamos anteriormente ${ }^{1}$. Otros monarcas de la Edad Moderna tuvieron a su servicio plateros y joyeros italianos que pudieron o no influir, según los casos, en los plateros nacionales. Por otra parte existieron orfebres italianos que por distintos motivos emigraron a España para trabajar en diversas ciudades, $y$ a veces dejaron impronta de su estilo en los talleres locales. Sin embargo, todo esto no influyó definitivamente en la trasformación de los estilos españoles de la Edad Moderna, especialmente en el cambio radical que trajo el Renacimiento. Este se produjo en el arte de la platería más por los modelos genéricos de arquitectura, escultura y ornamentación, difundidos a través de los grabados, que por las piezas italianas de importación. Estas generalmente, además de no ser muchas, se hallaban en colecciones privadas y por lo tanto no podían ejercer su influencia en los talleres ciudadanos.

Por otra parte sabemos que algún orfebre de primera línea tenía una gran biblioteca con los principales tratados teóricos del renacimiento italiano, como es el caso del mencionado Juan de Arfe ${ }^{2}$. Seguramente los principales plateros españoles conocieron también las colecciones de dibujos y grabados, tanto de temas decorativos, como de formas estructurales, que corrían por la península, y a través de ellos cambiaron su estilo y sus modos de trabajo. Ya en la segunda mitad del siglo XVI la Varia Conmesuración de Juan de Arfe con su repertorio de dibujos de platería tuvo una influencia definitiva en los talleres españoles, encontrándose bastantes ediciones de esta obra en fechas posteriores ${ }^{3}$.

A lo largo del siglo XVII la platería española se independiza de las corrientes italianizantes y crea su estilo propio y característico bastante diferenciado del italiano, pero, sin embargo, en el último tercio del siglo las corrientes barrocas europeas vuelven a influir en el estilo de la platería española, y esta vez vuelve a notarse el estilo italiano con más fuerza, aunque ahora procedente del reino de Nápoles y de la ciudad de Roma.

1. Sanz, MJ.: Juan de Affe y Villafañe y la custodia de la catedral de Sevilla, Sevilla, 1979, págs. 43-49.

2. Barrio, J.L.: "El platero Juan de Arfe y Villafañe y el inventario de sus bienes", Anales del Instituto de estudios madrileños, tomo XIX, Madrid, 1982.

3. Arfe, J.: De varia commesuración para la esculptura, architectura y obras de iglesia, Sevilla, 1587, De varia commesuración para la esculptura y architectura, Sevilla, 1585, edic. de Bonet, A., págs. 61 y 62, Sanz, M.J.: "aspectos teóricos de la obra literaria de Juan de Arfe", ACTAS DEL VIII Congreso Nacional de Historia del Arte, Cáceres, 1990-93, Tomo I, págs. 317-320. 
Durante el siglo XVIII la influencia italiana se mezcla con la francesa, corriente esta que termina por desbancar a la italiana, debido naturalmente a la llegada de la dinastía borbónica a España a comienzos de la centuria. No obstante, la influencia italiana se mantendrá sin desaparecer del todo, gracias a la labor de Carlos III, primero rey de Nápoles y más tarde de España, que favoreció a su llegada a la Península la venida de artistas y artesanos, y su asentamiento en ella.

Así pues las relaciones políticas entre ambos países van acompañadas de las relaciones culturales, y de la misma manera que las personas de la familia reinante van y vienen de España a Nápoles, los artistas y artesanos viajan con ellas. El mismo motivo hace que las jerarquías eclesiásticas se trasladen de un reino a otro, y así obispos y arzobispos ejercen su ministerio en ambos reinos sucesivamente, con lo que su mecenazgo cultural se traslada de uno a otro lado del Mediterráneo.

Todo este trasiego de personas trae consigo un trasiego de ajuares, entre los que siempre se hallan piezas artísticas, ya sean de pintura, de escultura, o de metales preciosos. Estas últimas constituyen quizá el grupo de mayor importancia, ya que su valor material las hacía ser piezas fundamentales a la hora de los regalos u ofrendas. Por otra parte su belleza artística o su rareza hicieron siempre de ellas objetos muy apreciados por sus mismos propietarios.

No obstante las piezas de orfebrería italiana en España no son demasiado numerosas, o al menos no hay demasiadas referencias a ellas, aunque hay que hacer notar que no se han realizado trabajos en este sentido. En general, las obras existentes proceden de compras realizadas en Italia por nobles y magnates que las traían a España a la vuelta de sus misiones políticas, religiosas o guerreras, o bien, en el caso de los reyes, podían proceder de encargos concretos o de regalos. Sabemos, por ejemplo, que Felipe II poseía una maravillosa colección de vasos de cristal de roca tallados -a menudo con adornos de oro y piedras-, y que hoy día están desaparecidos, muy semejantes a los del Tesoro del Delfín, que seguramente eran obras florentinas o milanesas, ya que la técnica del cristal tallado no era muy habitual en España.

Otra vía por la que las piezas de plata y oro podían venir a la Península era la del intenso comercio mediterráneo, pero no tenemos demasiadas noticias de piezas de plata traídas expresamente para vender a España.

El camino que hasta ahora mejor conocemos es el de la jerarquía eclesiástica, ya que precisamente algunos de sus miembros solían traer piezas de Roma cuando iban a los cónclaves o a cualquier otro negocio religioso, o bien de Nápoles donde habían desempeñado algún cargo eclesiástico. Si se trataba de simples frailes, podían recibir el encargo de su convento de traer reliquias u objetos para el culto.

La difusión del estilo de estas piezas italianas nunca fue demasiado amplia ya que los objetos permanecieron en el convento o iglesia para la que habían sido comprados, teniendo sólo acceso a ellas los componentes de la comunidad y los 
fieles que frecuentaban el templo. Sólo en el caso de algunas piezas de gran envergadura, que se hallaban además en templos multitudinarios, puede decirse que pudieron tener influencia en el arte de los plateros locales. En el caso de las piezas compradas o regaladas a nobles o reyes su difusión fue aún menor, pues sólo se usaron privadamente, y quizá sólo los plateros de la Corte las conocieron.

\section{LAS PIEZAS ITALIANAS EN SEVILLA.}

La ciudad posee algunos importantes conjuntos de piezas italianas, en su mayoría procedentes del sur, aunque también las hay romanas. En la provincia se hallan también algunas obras, relacionadas en su mayoría con casas nobles cuyos miembros desempeñaron cargos políticos en Italia, y trajeron en sus ajuares objetos de plata, oro $u$ otros metales.

En la provincia de Sevilla las piezas más antiguas conocidas de origen italiano son un portapaz, una cruz de altar y dos candeleros, todo a juego, existentes en la Colegiata de Osuna, piezas datables hacia 1600 , pertenecientes a los duques de Osuna, que estuvieron relacionados con Venecia y Nápoles como embajadores. Estas obras fueron ya estudiadas y publicadas por nosotros hace algunos años 4 . Se hallan realizadas en bronce y mármol, dentro del más puro estilo manierista, y fueron donadas por Doña Isabel de la Cueva en 1612. Del mismo estilo son unas vinajeras con su bandeja realizadas, como las piezas anteriores, en jaspe rojo y bronce dorado, además de haber sido donadas por la misma señora y en la misma fecha. No obstante, la bandeja es una burda imitación de la original que no coincide con la descripción que de ella se halla en la documentación al respecto. Como puede verse es un conjunto para la mesa de altar que los duques tenían en su capilla para el culto habitual. Aunque las piezas no tienen manca ni inscripciones puede afirmarse que son obras italianas a juzgar por su estilo y técnica. En primer lugar en el portapaz se representa al Ecce Homo con una iconografía absolutamente italiana, que concuerda con la línea estilizada del resto de las piezas. En lo que se refiere a las técnicas y a los materiales, estos son bastante ajenos a los utilizados y realizados en España, por lo que pueden considerarse como piezas italianas, aunque la documentación no lo especifique, situándolas probablemente como procedentes del Reino de Nápoles.

Del Reino de Nápoles procede, en este caso con seguridad absoluta, uno de los más importantes legados arzobispales a la catedral de Sevilla, debido al cardenal-arzobispo Don Jaime de Palafox y Cardona, que ocupó la sede sevillana entre 1685 y $1700^{5}$.

4. Sanz, M. J.: Orfebreria en la Colegiata de Osuna, Sevilla, 1979, págs. 18, 32 y 42.

5. Sanz, M.J.: "Escultura y orfebrería panormitanas en la catedral de Sevilla", Archivo Hispalense, $n^{\circ} 188$, Sevilla, 1982, págs. 75-91. 
El legado de Palafox a la archidiócesis de Sevilla fue riquísimo, tanto en vida como después de muerto. Entre las piezas que mandó realizar en vida se encuentra el grandioso altar de plata que hizo Juan Laureano de Pina, en las últimas décadas del siglo XVII. Intervino también económicamente en la urna de plata para el cuerpo de San Fernando, que realizó el mismo platero, y que promovió el cabildo de Capellanes Reales junto con la monarquía reinante. Esta obra; sin embargo, no pudieron verla terminada, ni el rey que protegio su construcción -Carlos $\Pi$-, ni el mismo arzobispo, ya que ambos murieron en 1700 y la urna se terminó en $1719^{6}$.

El Expolio después de la muerte del cardenal dejó al tesoro de la catedral valiosísimas piezas como el excepcional relicario de Felipe V de Francia y Leonor de Borgoña -datable en la primera mitad del siglo XIV ${ }^{7}$-, y la magnífica cruz procesional de plata y esmalte, con crucificado de plata superpuesto de factura miguelangelesca. No obstante, el mayor interés de sus donaciones reside en el grupo de piezas de plata que él trajo de Palermo, donde había ejercido como arzobispo entre 1677 y 1685, a propuesta de Carlos II, y de donde se trasladó a Sevilla como arzobispo de la sede hispalense.

Estas piezas, aún conservadas en la catedral, son: una imagen de plata de Santa Rosalía de más de medio cuerpo y de tamaño algo mayor del natural, un relicario esmaltado con las reliquias de la misma Santa, y una pequeña escultura de bronce, plata, oro y piedras preciosas, que representa a la Iglesia.

La imagen de Santa Rosalía (fig.1), mide $106 \mathrm{cmts}$. de altura, y representa a una joven de bellas facciones y aire berninesco. En el pecho lleva un broche de oro con su reliquia, que destaca sobre una túnica lisa. El manto, de ondulantes pliegues, finge un tejido adamascado, y cuelga sobre una peana de bellísima decoración vegetal barroca. Sus temas ornamentales y su estilística debieron influir en algunos orfebres sevillanos que trabajaron para el arzobispo, especialmente en Juan Laureano de Pina y sus discípulos, como puede apreciarse en obras como el altar de plata de la catedral, realizado en su mayor parte durante el gobierno de Palafox. Santa Rosalía lleva las marcas de la ciudad de Palermo, del contraste y del autor. La marca de la ciudad consiste en un águila con las alas desplegadas, y bajo ella las iniciales de la ciudad, R U P, cuya lectura es Regia Urbs Panormitana ${ }^{8}$. La marca del contraste es V.D.C.81, la cual, según el marcaje de la ciudad de Palermo y en general de la mayoría de las ciudades del Reino de Nápoles, consiste en colocar las iniciales del nombre y apellido del contraste o cónsul de plata de la ciudad, seguidas de las dos últimas cifras del año en que se realizó la pieza. En

6. Sanz, M.J.: Juan Laureano de Pina, Sevilla, 1981, págs.109-110.

7. Sanz, M.J.: "Notas sobre la restauración del relicario de Felipe V y Juana de Borgoña", Goya, n's 229-230, Madrid, 1992.

8. Para la lectura de las marcas de las ciudades de Sicilia es útil la consulta de Accascina, M.: $I$ Marchi delle Argenterie e Orificerie Siciliane, Busto Arsicio, 1976. 
este caso las iniciales se leerían V.D. Cónsul, 1681, aunque las iniciales del nombre no han podido ser identificadas. Finalmente la tercera marca que aparece en la escultura se expresa con el siguiente anagrama, A.L.C., y corresponde al autor. Para la interpretación de esta marca es fundamental la lectura de la inscripción que aparece en la peana.

Esta, que se halla incompleta, dice: Antoninus Lo. Cas(roto)Normi (roto) A.L.C. fecit An:Do:MDCL(roto). En 1923, año en que esta inscripción fue recogida por vez primera ${ }^{9}$, aún podía leerse la fecha completa, que era 1688. Como puede verse la inscripción recoge el nombre incompleto, la marca del autor, y la fecha. Por lo que respecta al nombre, es evidente que se corresponde con las iniciales de la marca que le siguen, aunque, como podemos observar, la inscripción se halla incompleta. Nosotros dimos anteriormente dos versiones del apellido, la primera en 1976 en que leímos: Antoninus Lorenzo Castelli ${ }^{10}$; más tarde, en 1982 , la lectura detenida de la inscripción y la consulta de bibliografía especializada " nos hizo pensar en otra alternativa, leyendo Antoninus Lorenzo Castronormi ${ }^{12}$. Una nueva actualización bibliográfica nos permite proponer una tercera hipótesis, que se apoya en lo siguiente. En la catedral de Palermo existe una urna de plata que contiene los restos de Santa Rosalía, pieza que fue realizada entre 1631 y 1637. Intervinieron en ella Mariano Smiriglio como diseñador, y los orfebres: Giuseppe Oliveri, Francesco Rivelo, Gian Cola Viviano y Matteo Lo Castro, como orfebres ${ }^{13}$. Es evidente que el último orfebre coincide en el segundo nombre y en el apellido con el autor de la Santa Rosalía de la catedral de Sevilla, pero la diferencia de 50 años hace imposible que sea el mismo. No obstante, podríamos sacar algunas consecuencias de la comparación de ambos nombres. Primeramente que el autor de la Santa Rosalía sevillana podría ser un descendiente del que 50 años antes había colaborado en la urna de la catedral de Palermo, y en segundo lugar podríamos establecer quizá más exactamente el apellido simplemente como Castro, y pensar que la palabra Normi podría corresponder a un toponímico cuya primera parte, como la final del apellido hubiera desaparecido con la rotura. Así, la posible reconstrucción de la inscripción sería: ANTONINUS. LO. CAS(TRO PA)NORMI(TANUS) A.L.C. FECIT AN. DO. MDCLXXXVIII.

Con respecto a la fecha se observa una diferencia de 7 años entre las marcas de la escultura -1681- y la inscripción de la peana -1688-, que puede interpretarse de dos formas, bien como el tiempo que pasó entre la realización de la escultura y el de la peana, o bien, entre la realización de ambas y la donación a la catedral. En cualquier caso la escultura fue realizada mientras Palafox estaba en Palermo,

9. Exposición de Valdés Leal y Arte Retrospectivo, Catálogo, Sevilla, 1923, pág.80.

10. Sanz, M.J.: Orfebrería sevillana del Barroco, Sevilla, 1976, tomo I, pág. 254.

11. Accascina, M.: ob.cit.

12. Sanz, M.J.: "Escultura y orfebrería panormitanas en Sevilla", Archivo Hispalense, n 198 , Sevilla, 1982, pág. 79.

13. Collura, P.:Santa Rosalía nella storia e nell'arte, Palermo, 1977, pág.85. 
y regalada a la catedral cuando ya era arzobispo de Sevilla. Muy probablemente el arzobispo se hizo devoto de la Santa durante su estancia en Palermo, ya que es la patrona de esta ciudad y tiene un hermoso santuario en las cercanías, sobre una colina. La imagen de mármol que reside en él fue recubierta de plata, como regalo de Carlos III durante su gobierno en Nápoles ${ }^{14}$, según se lee en la peana de la imagen.

En la catedral de Sevilla, y relacionado con el estilo de Santa Rosalía se halla una pequeña imagen femenina $-28 \mathrm{cmts} .-$, que puede representar a la Virgen, $o$ quizá mas propiamente a la Iglesia (fig.2). Se trata de una figura de plata con corona y cetro de oro y pedrería, que se sienta sobre un suntuoso sillón de bronce dorado. La escultura, de cuerpo completo, presenta semejanzas estilísticas y tipológicas con la de Santa Rosalía; el mismo rostro oval, el cuello esbelto, la postura de las manos, y sobre todo el gran movimiento de paños que tienen vida por sí mismos. Igualmente presenta túnica lisa y manto decorado. El modelo está además claramente vinculado a una serie de figurillas de santos napolitanos que encontramos en los museos italianos, entre ellos en el Palacio Venecia en Roma, así como los presentados en la Exposición de Orfebrería Barroca celebrada en Nápoles en 1980. Por todo ello, aunque no lleva marca ni inscripción alguna puede considerarse como obra italiana contemporánea de la gran Santa Rosalía de plata, y probablemente regalada por Palafox.

De Palermo debe proceder también un relicario de oro y esmalte en forma de cajita oval, que contiene un hueso de Santa Rosalía (fig.3). La caja presenta una guirnalda calada de rosas esmaltadas multicolores, y una tapa de cristal para poder contemplar la reliquia. Este tipo de esmalte pintado es de origen claramente napolitano, por lo que, unido a la reliquia que contiene, nos hace calificarlo como obra panormitana contemporánea de Santa Rosalía, y legada igualmente por Palafox.

Relacionados con las donaciones del cardenal Palafox parecen estar dos cálices existentes en dos conventos sevillanos, ya que ambos llevan la marca de Palermo, y sus fechas son próximas a la de Santa Rosalía. El más sencillo se halla en el convento de monjas agustinas de la Encarnación. Se trata de una pieza de plata dorada con fina decoración grabada de punteado, cuyos temas vegetales tienen un claro aire seiscentista, y su estructura no coincide exactamente con los modelos españoles, aunque es bastante semejante. Lleva tres marcas, la de la ciudad de Palermo -el águila explayada y bajo ella las siglas de la ciudad, R U P-; la del contraste GO84, que significa Giacinto Omodei, año 1684; y la del autor que consiste en una $\mathbf{A}$ y una posible $\mathbf{M}$, con cuyas iniciales se conocen varios nombres de orfebres en Palermo en esa época, tales como Antonio Mercurio, Antonio Mollo y Antonio Meringari, todos documentados a fines del siglo XVII y a comienzos del XVIII ${ }^{15}$.

14. Collura, P.: ob. cit., pág. 183, fig. 97.

15. Sanz, M.J.: " Escultura y orfebrería panormitanas...", pág.82. 
El otro cáliz (fig. 4) se halla en el convento de carmelitas de San José, llamado vulgarmente Las Teresas, y consiste en una hermosa obra de plata dorada con incrustaciones de coral, que lleva las mismas marcas de ciudad y contraste que el cáliz anterior, pero no presenta marca de autor ${ }^{16}$. La coincidencia de fechas de ambos cálices hizo que nosotros, en un trabajo anterior ya citado, las relacionáramos con las donaciones del cardenal Palafox, que pudo haberlas comprado en Palermo, ya que en esa fecha de 1684 se hallaba en dicha ciudad como arzobispo, y posteriormente regalarlas a los conventos que actualmente las poseen.

Bastante más tardías son otras dos piezas italianas conservadas en la catedral de Sevilla, pues corresponden a la segunda mitad del siglo XVIII. Una de ellas es un ostensorio que regaló el Cardenal Solís en 1780, y la otra es la urna para el Jueves Santo que regaló en canónigo Rosal en 1771.

El ostensorio es una magnífica pieza de plata dorada que presenta una tipología muy propia del barroco italiano, así como un abigarramiento decorativo inusual en la platería española (fig.5). Su estructura presenta una peana ovalada de perfil mixtilíneo y un cierto abombamiento donde aparecen escenas de la vida de San Juan Nepomuceno, enmarcadas en temas vegetales. El astil está formado por la figura del Santo, que en una forzada postura de torsión mira hacia arriba, donde se encuentra la Virgen de Loreto, y sobre ella el sol. Este tiene forma oval con perfil interior mixtilíneo, y el exterior formado por rayos biselados de distintos tamaños. Todo el viril y parte de los rayos están cubiertos por el programa sacramental superpuesto que se compone de espigas, racimos de uvas, siete arcángeles y la Virgen de Loreto en la base, rematándose en una cruz con ráfagas.

La estilística de las imágenes es en general de aspecto muy cortesano, especialmente en la representación del Santo. En lo que se refiere a la estructura y a los modelos decorativos hay que decir que, tanto el perfil de la peana como el del interior del sol, coinciden con las líneas arquitectónicas del Barroco italiano. La pieza lleva marcas e inscripciones, las primeras se encuentran en la peanà y son dos, una formada por las letras X J, y otra ilegible. En cuanto a la inscripción, que corre por el borde dice así: "Con motivo del Cónclave del anno 1774 que se finalisó el de 1775, a 15 de febrero, en que fue electo Nuestro muy Sancto Padre Pio VI vino a Roma el Eminentísimo y Excelentísimo Sr. Cardenal di Solís, Arzobispo de Sevilla y compró este ostensorio para su Sancta Ygleçia por memoria de su afecto" 17.

16. Sanz, M.J.: "Escultura y orfebrería panormitanas...", págs.82-83. Esta pieza junto con otras del mismo estilo y técnica serán estudiadas en la segunda parte de este trabajo.

17. El estudio y descripción de la obra, así como la lectura de la inscripción con la fecha icluída, y las dos marcas que en la pieza aparecen, una ilegible y otra no interpretada hasta ahora, fue dada a conocer por nosotros en $L a$ orfebrería sevillana..., tomo II, Sevilla, 1976, pág.173, posteriormente Palomero, J. en V.V.A.A.: La Catedral de Sevilla, Sevilla, 1984, págs. 627-628, dio la interpretación de su iconografía. 
El material empleado en la obra es plata dorada y blanca, perlas, piedras preciosas y falsas, y coral. En 1781 sufrió una pequeña reforma que sustituyó algunos adornos de bronce, por otros de plata, y que estuvo a cargo de Juan Bautista Zuloaga ${ }^{18}$, pero esta reforma no alteró prácticamente el nada a la pieza.

La otra pieza, la uma de oro para el Jueves Santo, de la que también dimos noticias anteriormente ${ }^{19}$, es contemporánea del ostensorio anterior, pero el proceso de llegada a Sevilla fue diferente. La obra fue encargada por el canónigo Jerónimo Ignacio del Rosal al platero romano Luis Valadier en 1771, y estrenada al año siguiente. Luis Valadier fue una figura de gran renombre en la Roma de la segunda mitad del siglo XVIII, y se conservan bastantes obras de su mano, no sólo en su país de origen, sino en otros varios países de Europa, entre ellos Inglaterra, Portugal y España.

Los Valadier eran una familia de plateros de los que se conservan importantes colecciones de dibujos en distintos museos y bibliotecas europeas, y como puede verse por su apellido procedían de Francia. Allí nació Andrea Valadier en 1695, emigrando a Roma en 1741, donde entró a trabajar en un taller de platero. En 1726 nació su hijo Luis, autor de la pieza sevillana, y quizá el más importante platero romano de su época. Su trágica muerte suicidándose en el Tiber ocurrió en 1785. Su hermano Giovanni y su hijo Giuseppe ejercieron también como orfebres, pero el último fue además un famoso arquitecto ${ }^{20}$.

El sagrario sevillano fue una pieza cuidadosamente pensada y diseñada, cuyo dibujo se conserva en una colección londinense (fig.6) ${ }^{21}$. La obra, repujada y cincelada en oro, es de forma cúbica, con perfiles ondulados en sus ángulos, de los que cuelgan angelillos, y cubierta con cupulilla que soporta al pelícano con sus crías. En los frentes de la cupulilla se levantan veneras rocallescas, y de los ángulos surgen cuatro sigmas vegetales que se unen bajo la peana del pelícano. En las cuatro paredes laterales aparecen medallones de forma oval enmarcados con guirnalda de laurel, que contienen las siguientes escenas: La Oración en el Huerto, La Última Cena, La Trasfiguración y La Piedad (fig.7). La pieza es una excepcional obra del barroco tardío romano que tiene, sin embargo, un sentido de la fragilidad rococó, y algunos elementos decorativos que ya anuncian el Neoclasicismo. Esta suntuosa urna se halla colocada sobre una peana de plata blanca y bronce dorado, que fue realizada por el platero flamenco Francisco Leclare en 1774, y pagada por el mismo canónigo que regaló la urna. Este basamento sigue las directrices estéticas de la urna, aunque las rocallas aquí son evidentes, como corresponde a una estética afrancesada. La pieza tiene una estructura trocopiramidal de superficies laterales curvilíneas, destacando en su parte inferior un falso basamento.

18. Palomero, J.: ob.cit., págs. cit.

19. Sanz, M.J.: Orfebrería sevillana..., tomo II, pág. 173.

20. V.V.A.A.: Valadier Three Generation of Roman Goldsmiths. An exhibition of Drawings and works of Art, London, 1991, págs.7-8.

21. Ibidem, págs.82-83 y 158-159. 
En el aspecto decorativo hay que hacer notar el desarrollo de sigmas y ménsulas en los ángulos, y los medallones adosados a cada una de las caras. La obra tiene un fondo de plata blanca con decoración de celdillas, y sobre éste se adosan los medallones de bronce dorado. En lo que se refiere a la representación iconográfica de los medallones, contiene dos ciclos, uno alusivo a la Pasión de Cristo, y otro alusivo a la Eucaristía. En el primero las escenas representadas son: El Ecce Homo, Cristo atado a la columna, El Camino del Calvario y Cristo clavado en la cruz. En el segundo las escenas son: El Arca de la Alianza, El Tabernáculo de los sacrificios, Los Panes de la Propiciación y Acab y Joreb portadores del racimo de uvas. Como vemos se repiten las prefiguraciones de la Eucaristía en el Antiguo Testamento, estableciendo paralelos entre la muerte de Cristo y la instauración de la Eucaristía. Estos paralelos arrancan ya del siglo XVI, propugnados por los teólogos de Trento, y plasmados en obras de gran envergadura como las custodias de la segunda mitad del siglo XVI. La de Juan de Arfe en la catedral de Sevilla es el más completo ejemplo de ello ${ }^{22}$. Es lógico pensar que esta urna y su peana hayan tomado la inspiración de sus temas en la custodia de Arfe, aunque su interpretación y su estética, dados los 200 años que median entre una y otra pieza hayan cambiado bastante. Por otra parte sabemos que urna y peana fueron hechas para colocar la Eucaristía dentro de la custodia de Arfe, desempeñando el papel de arca eucarística el Jueves Santo, en el mismo lugar en que se colocaba el ostensorio el día del Corpus. Así, y siguiendo la liturgia cristiana, el Cuerpo de Cristo se mostraba a los fieles como triunfante y visible en día del Corpus, y por el contrario permanecía oculto en la urna durante los días de su pasión: el Jueves y parte del Viernes Santo. La custodia, con la urna eucarística en su interior, se colocaba a su vez dentro del Monumento que se instalaba en el trascoro de la catedral, y allí permanecía durante toda la Semana Santa. Hoy día aunque la liturgia cristiana sigue los mismos pasos, ya no se monta el monumento durante la Semana Santa, y la urna se coloca en el centro del altar de plata.

22. Sanz, M.J.: Juan de Arfe..., Sevilla, 1979. 


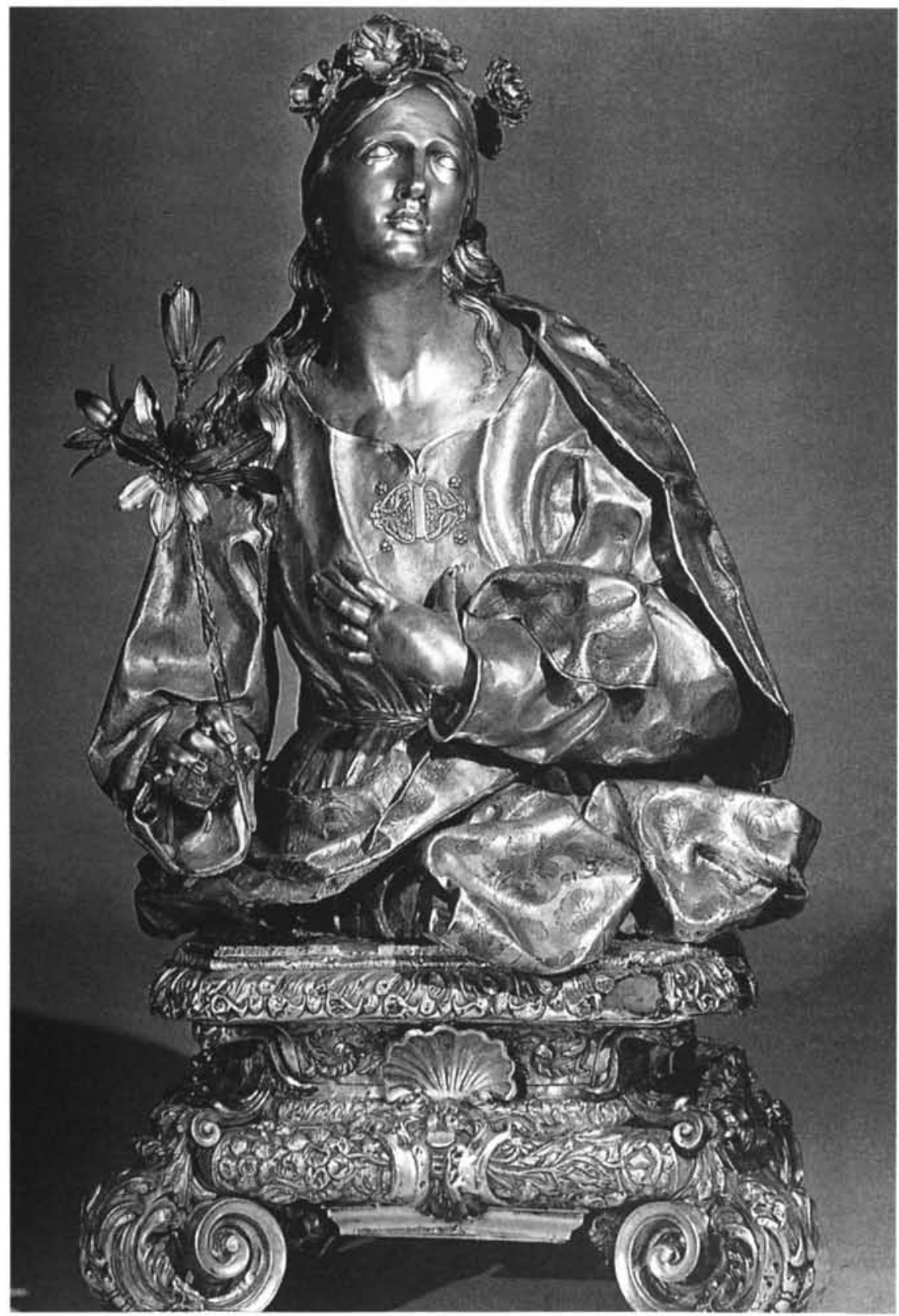

Fig. 1. Sta. Rosalía, Catedral de Sevilla. 


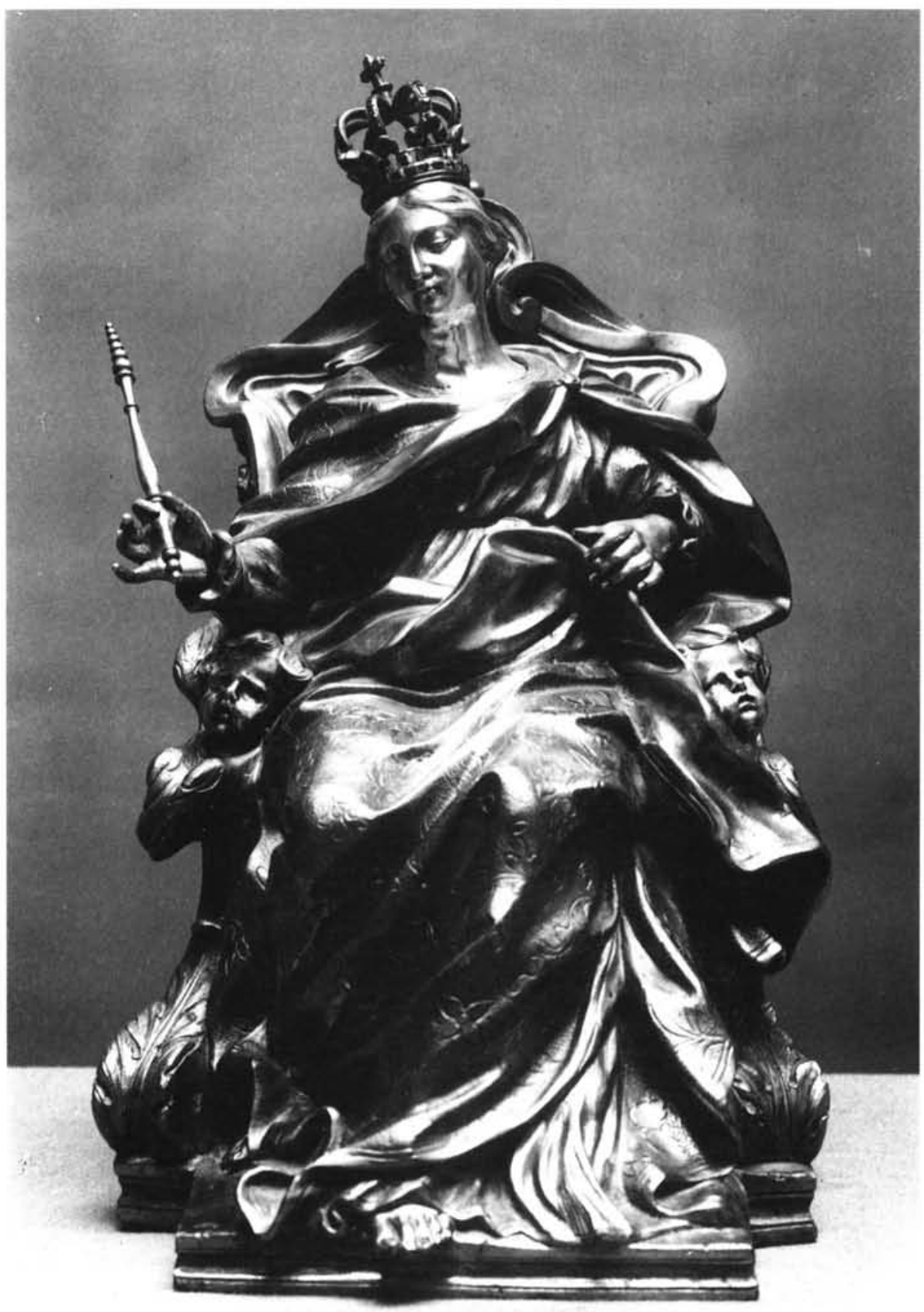

Fig. 2. Imagen de la Iglesia, Catedral de Sevilla. 


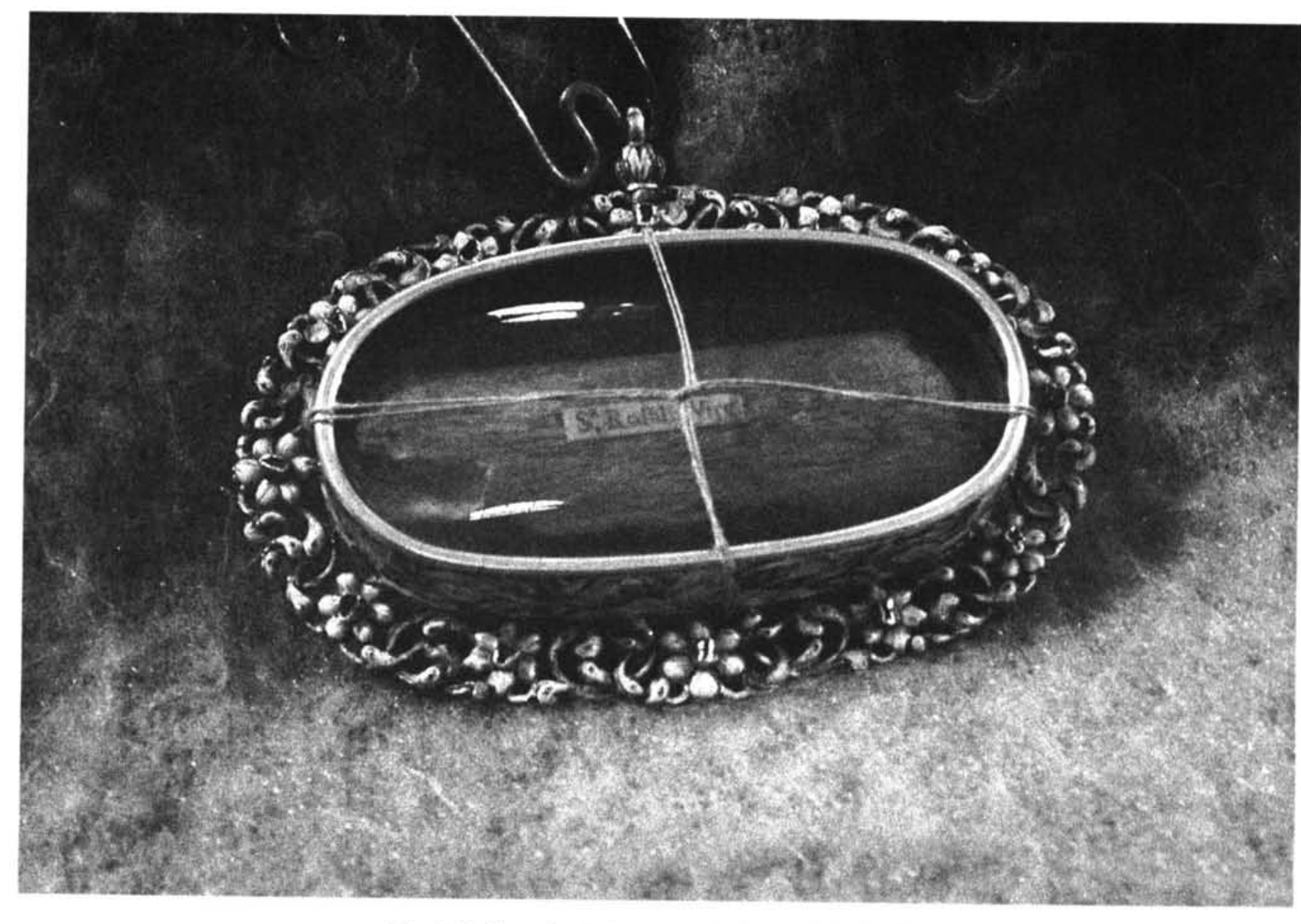

Fig. 3. Relicacario de Sta. Rosalía, Catedral de Sevilla. 


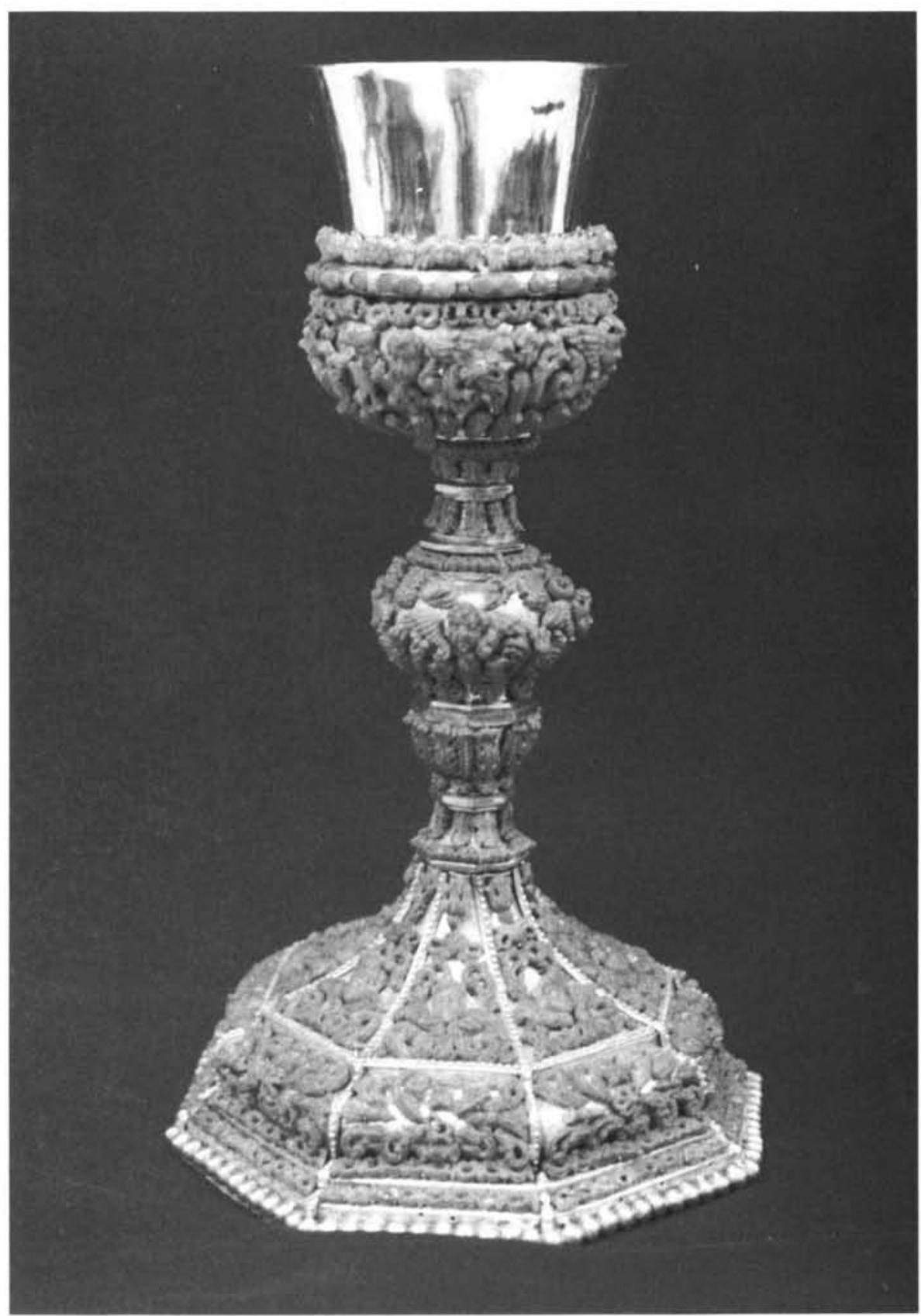

Fig. 4. Cáliz de Corales, Convento de San José (Las Teresas) de Sevilla. 


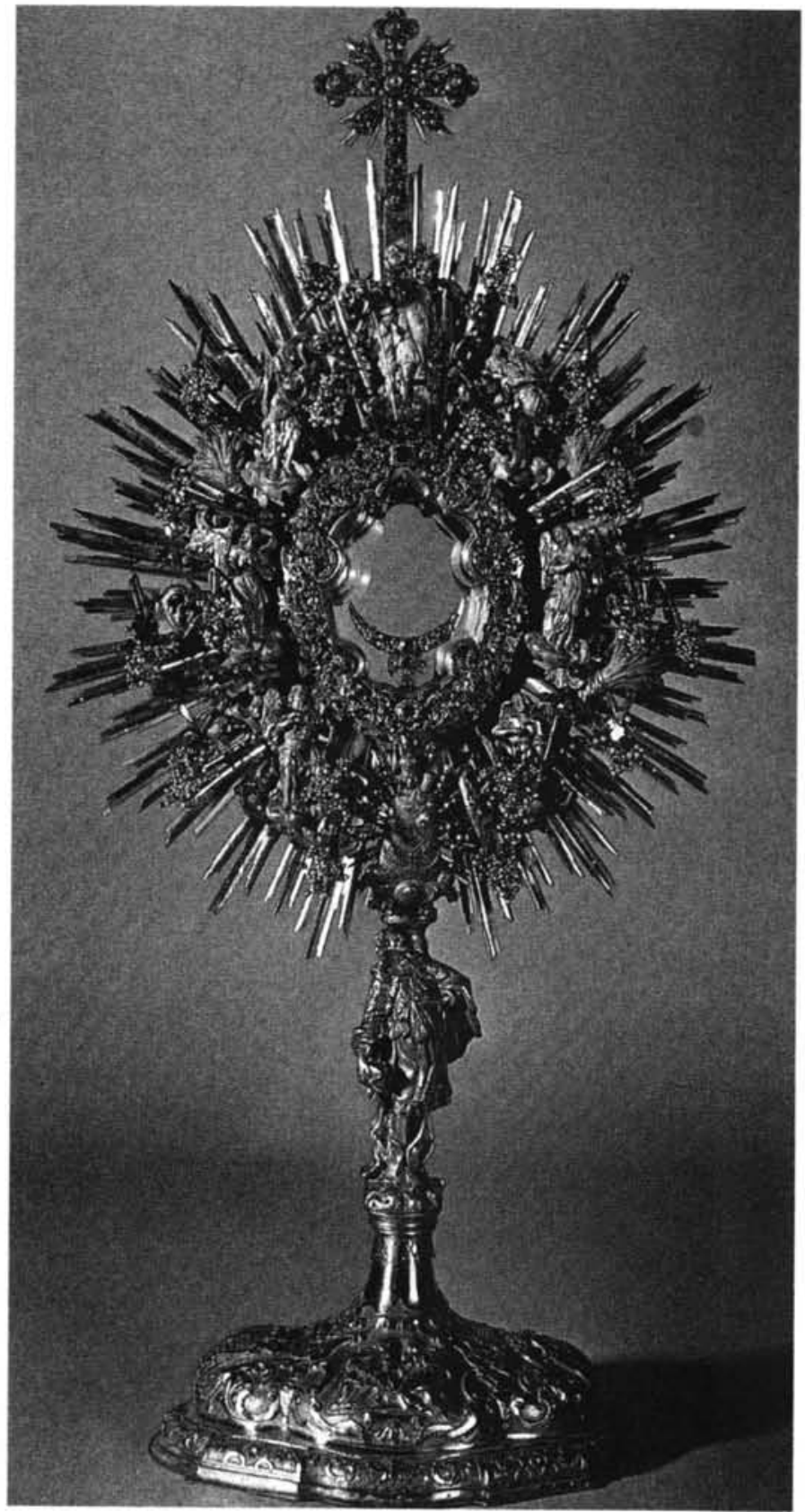

Fig. 5. Ostensorio del Cardernal Solís, Catedral de Sevilla. 


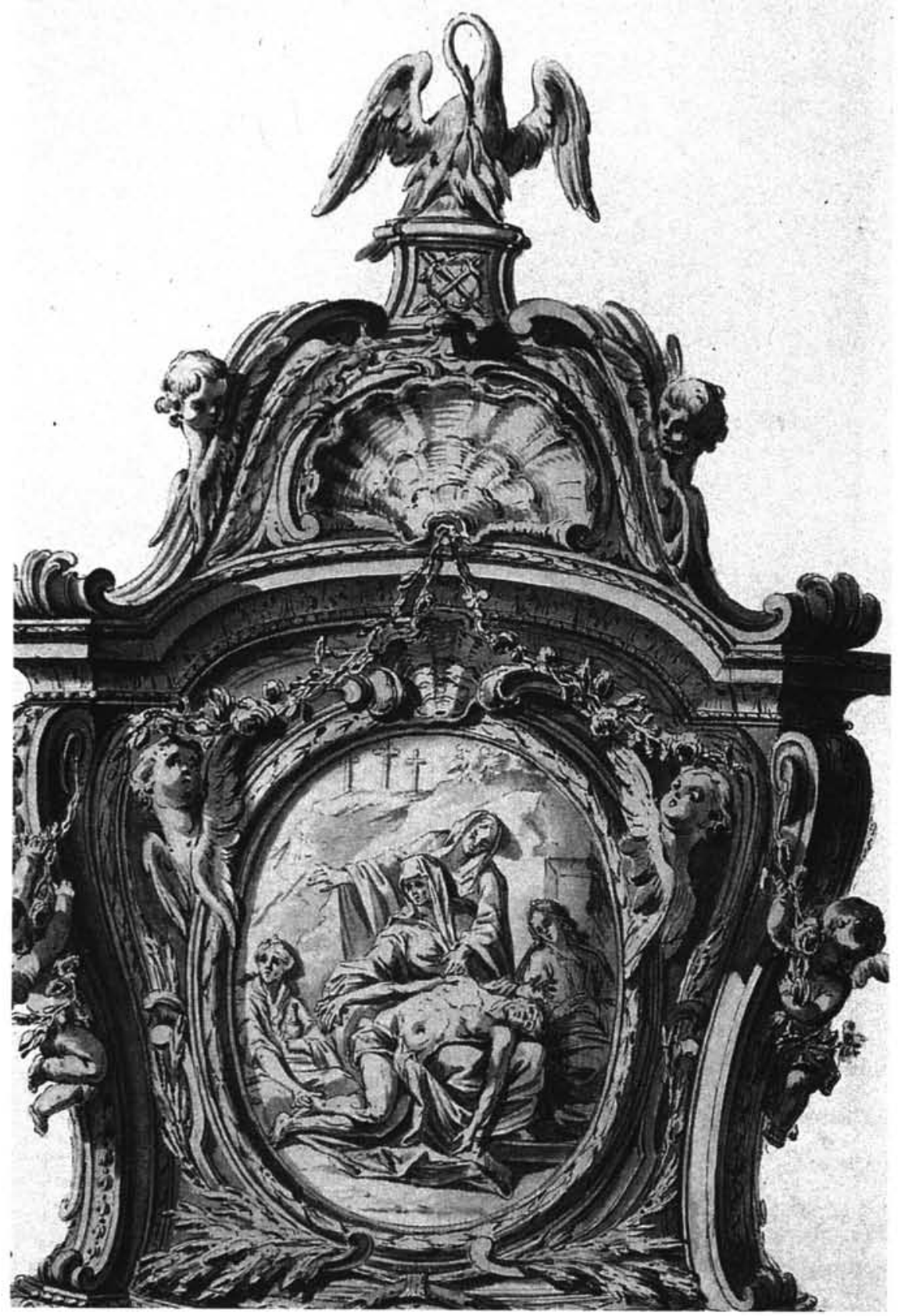

Fig. 6. Dibujo previo a la realización del Sagrario de Luis de Valadier, Londres, Colección privada. 


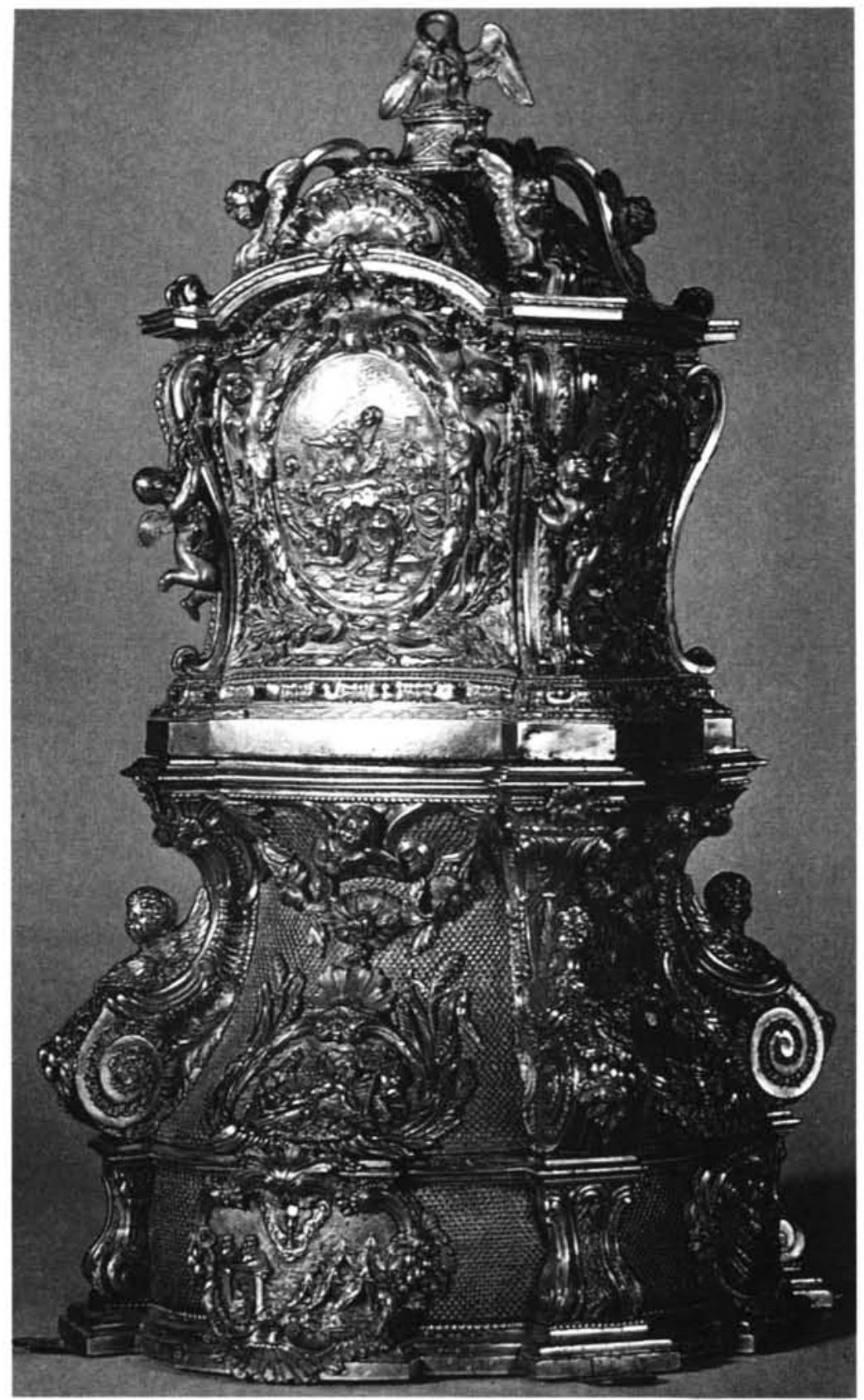

Fig. 7. Sagrario con su peana de Luis de Valadier y Fco. Leclare, respectivamentete, Catedral de Sevilla. 